\title{
Aging and path integration skill: Kinesthetic and vestibular contributions to wayfinding
}

\author{
GARY L. ALLEN, KATHLEEN C. KIRASIC, and MATTHEW A. RASHOTTE \\ University of South Carolina, Columbia, South Carolina \\ and \\ DANIEL B. M. HAUN \\ Max Planck Institute for Psycholinguistics and \\ F. C. Donders Centre for Cognitive Neuroimaging, Nijmegen, The Netherlands
}

\begin{abstract}
In a triangle completion task designed to assess path integration skill, younger and older adults performed similarly after being led, while blindfolded, along the route segments on foot, which provided both kinesthetic and vestibular information about the outbound path. In contrast, older adults' performance was impaired, relative to that of younger adults, after they were conveyed, while blindfolded, along the route segments in a wheelchair, which limited them principally to vestibular information. Correlational evidence suggested that cognitive resources were significant factors in accounting for age-related decline in path integration performance.
\end{abstract}

Wayfinding, defined as destination-guidedlocomotion, is a common yet very important activity in everyday life throughout the adult years (Golledge, 1999; Kirasic, 2001). Two common and complementary means of wayfinding are piloting (i.e., orienting by means of external sources of information regarding position) and path integration (i.e., orienting by means of external and internal sources of information regarding direction and speed of movement; Allen, 1999; Gallistel, 1990; Loomis, Klatzky, Golledge, \& Philbeck, 1999). Evidence from studies of route learning (Barash, 1994; Kirasic, 1991, 2000; Lipman, 1991; Lipman \& Caplan, 1992; Wilkniss, Jones, Korol, Gold, \& Manning, 1997) and memory for object location (Cooney \& Arbuckle, 1997; Evans, Brennan, Skorpanich, \& Held, 1984; Uttl \& Graf, 1993) points to an aging-related decrement in piloting, particularly in unfamiliar surroundings. However, the matter of age-related changes in human path integration has yet to be examined empirically.

The absence of prior research on this topic is noteworthy in light of the potential importance of path integration in navigational competence in everyday life. It has been hypothesized that path integration provides the neural and informational foundation for landmark-based piloting (Gal-

Assistance from Shayle Abelkop and Christy Miller, advice from Harriet Williams and Eleanor Gibson, generous and patient guidance from Jack Loomis, John Philbeck, and an anonymous reviewer, and financial support from a University of South Carolina College of Liberal Arts Scholarship Support (CLASS) grant are acknowledged with gratitude. Correspondence concerning this article should be addressed to G. L. Allen, Department of Psychology, University of South Carolina, Columbia, SC 29208 (e-mail: allen-gary@ @sc.edu).

Note-This article was accepted by the previous editorial team, headed by Neil Macmillan. listel, 1990; McNaughton et al., 1996) and, thus, is critically important in the ability to develop an integrated internal representation of one's spatial surroundings. The evidence regarding age-related decline in landmark-based piloting suggests two possibilities. On the one hand, the decline in landmark-based navigation could be the result of diminished path integration skill, particularly if path integration typically provides a supplemental informational foundation for piloting. On the other hand, path integration as the more basic process (Etienne, Berlie, Georgakopoulos, \& Maurer, 1998; Etienne, Maurer, Georgakopoulos, \& Griffin, 1999) may retain its operational integrity beyond the time that association-based piloting begins to reflect a general age-related decline in learning rate (Kirasic, Allen, Dobson, \& Binder, 1996). Differentiating between these two possibilities is a useful research objective.

An initial step toward that objective was taken in the present experiment, in which the performances of younger and older adults were compared on a simple return-toorigin task. In this laboratory-based procedure, participants are first conveyed along two segments of a triangular path and then attempt to walk the third segment directly back to the starting point; hence, it frequently is referred to as the triangle completion task. To be successful in this task, the participant must turn at the end of the second segment of the triangle to face the point of origin and then travel the correct distance to that point. This basic task has been used to study path integration in a number of species, including humans (Etienne et al., 1998; Gallistel, 1990; Loomis et al., 1993), and results have supported speculation that a similar mechanism for computing the return vector may be involved across species (Etienne et al., 1999).

Research on human behavior in the triangle completion task has shown large individual differences and has 
reflected strong influences of the outbound path on accuracy (Klatzky, Loomis, \& Golledge, 1997; Klatzky et al., 1990; Loomis et al., 1993). Several factors have been identified as major contributors to performance. Computation of the direction back to the origin and computation of the distance back to the origin after an outbound route are generally regarded as distinct but related operations (Allen, Kirasic, Dobson, Long, \& Beck, 1996; Anooshian \& Kromer, 1986; Berthoz et al., 1999; Klatzky et al., 1997; Loomis et al., 1999). Clearly, encoding outbound distances and encoding the outbound turn angle hold the key to understanding direction and distance errors during the return to the origin. Yet it is not the case that incorrect encoding of distance automatically leads a traveler to under- or overestimate the distance back to the origin, nor is it the case that error in encoding outbound turn angle inevitably leads a traveler to miscalculate the angle, but not the distance, back to the origin. Instead, encoding the outbound turn angle incorrectly should logically yield errors in both the angle taken back to the point of origin and the return distance traveled, whereas encoding just the outbound distance incorrectly should yield error only in the return distance traveled, with the angle of the return trip being relatively accurate (see $\mathrm{Fu}-$ jita, Klatzky, Loomis, \& Golledge, 1993; Klatzky, Beall, Loomis, Golledge, \& Philbeck, 1999; Klatzky et al., 1997; Klatzky et al., 1990; Loomis et al., 1999).

The central question addressed in this study concerned how perceptual information available during the two outbound route segments would affect the accuracy with which younger and older adults walked back to the point of origin. Specifically, the contributions of kinesthetic and vestibular sources of information regarding distances and direction were examined. After traveling two legs of the triangular route while being deprived of vision and hearing, participants who had been guided as they walked through the initial two segments of the triangular route could base their computations of direction and distance on information obtained through both kinesthetic and vestibular sources. In contrast, participants who had been conveyed in a wheelchair had to base their computations of turn and distance principally on information obtained through vestibular sources.

Previous studies have shown that both kinesthetic and vestibular sources of information are important complements to visual sources of information during path integration (Chance, Gaunet, Beall, \& Loomis, 1998) and that primary reliance on vestibular information sources has a detrimental impact on computation of the turn back to the point of origin (Sholl, 1989). In view of agingrelated decrements in the vestibular system (Ochs, Newberry, Lenhardt, \& Harkins, 1985), it might be expected that path integration after passive conveyance in a wheelchair would raise problems particularly for older adults. Consistent with this reasoning, it was hypothesized that passive locomotion in a wheelchair would result in less accurate path integration than would being led on foot, with the effect being greater for older adults than for younger.
Examining return angle and return distance separately provides some insight into how reliance on both kinesthetic and vestibular information during a return trip is affected by the availability of both types of information versus vestibular information alone during outbound distances and turns. As was mentioned previously, when self-produced movement (in the present case, the combination of kinesthetic and vestibular information) is involved, error in encoding the outbound turn angle or both the outbound turn angle and the distances should logically lead to incorrect angle and distance traveled during the return trip. Error in encoding outbound distance only should preserve the angle, relatively speaking, and lead to incorrect distance traveled. This expectation can provide a comparison point for what happens when perceptual information is present during the return trip that was not present during the outbound trip.

An additional issue under investigation in this study was the extent to which cognitive resources - specifically, information-processing speed and working memory capability - are involved in path integration skill. Agingrelated performance differences in a variety of tasks have been found to be mediated by information-processing speed, working memory capability, or both (Kirasic et al., 1996; Salthouse, 1991, 1996; Salthouse, Kausler, \& Saults, 1988), and previous research with younger adults has indicated that memory for path of movement may require cognitive resources (Gärling, Böök, \& Lindberg, 1985). Thus, it was reasonable to hypothesize that any age-related variance in the accuracy of either direction or distance response computation might be accounted for in terms of speed of processing or working memory capability, as assessed with separate tasks.

In summary, the purpose of the study was to examine age-related differences in adults' path integration skill, using a triangle completion task. Previous research indicated that the accuracy with which participants turned back to the point of origin and the accuracy with which they walked back to that point should be examined separately. However, previous work did not suggest an a priori hypothesis regarding which task component would be affected more by age. With regard to mode of travel, it was hypothesized that passive locomotion in a wheelchair would result in less accurate performance than would being led on foot, with the effect being greater for older adults than for younger. In addition, it was expected that age-related variance found in either the direction or the distance component of path integration skill would be mediated by measures of information-processing speed and working memory capability, representative of general cognitive resources.

\section{METHOD}

\section{Participants}

Data were collected from 30 younger adults and 24 older adults. Younger adults were volunteers from classes in the Department of Psychology at the University of South Carolina; older adults were healthy, independently living volunteers from community organizations for older citizens in Columbia, South Carolina. Four con- 
straints applied to all the participants. They judged their health to be at minimum "good," reported being right-handed, reported seeing without difficulty a brightly colored $10-\mathrm{cm}$ circle placed on the floor at a distance of $4 \mathrm{~m}$, and demonstrated the ability to stand up directly from a wheelchair without assistance. Additional descriptive information is provided in Table 1.

\section{Materials}

Subsidiary turn-to-target and walk-to-target tasks and the principal return-to-origin tasks were presented in a $6.60 \times 5.10 \mathrm{~m}$ unfurnished room. Opaque goggles and sound-deadening ear covers were worn by all the participants to prevent them from relying on visual and auditory information during task performance. Experimental tasks with which to assess working memory and speed of processing were presented in a separate $2.25 \times 2.60 \mathrm{~m}$ room furnished with a computer table, a desktop computer, and two chairs.

Subsidiary turn-to-target and walk-to-target tasks. The turnto-target task required the participant to stand in a viewing position, view a target on the floor at a 1-m distance from his or her standpoint, and then pivot while deprived of auditory or additional visual information so that the target was directly in front of him or her. The task included the following six target angles: $120^{\circ}, 135^{\circ}, 139^{\circ}$, $143^{\circ}, 146^{\circ}$, and $150^{\circ}$. These angles corresponded to the ones to be executed in the return-to-origin task. The walk-to-target task required the participant to stand in a viewing position, view a target at a variable distance from his or her standpoint, and then walk while deprived of auditory or additional visual information to where he or she stood directly over the target. The task included the following seven distances: 2.0, 2.6, 2.8, 3.4, 3.6, and $4.3 \mathrm{~m}$.

Principal return-to-origin task. For this path integration task, six triangular paths, representing a combination of outbound route segments $(2 \times 2 \mathrm{~m}$ vs. $2 \times 3 \mathrm{~m})$ and outbound turn angles between the segments $\left(60^{\circ}, 90^{\circ}\right.$, or $\left.120^{\circ}\right)$ were marked on the floor of the room. While being led on foot, the participant's movement was controlled by leading him or her as he or she held onto plastic grips in place on a detached bicycle handlebar. Passive transport along the routes was accomplished with the use of a standard wheelchair with attached footpads. The direction and distance error on each trial was assessed by marking the participant's stopping point with adhesive dots on the floor and later measuring the distance traveled and the angle taken in reference to the stopping point after the second segment in the triangular path. At the end of each trial, the participant was led to a waiting place within the room, and after the next trial was prepared, he or she was led to the starting position. Thus, the path back to the starting position was indirect, and there was no direct feedback provided regarding the accuracy of performance. Two versions of the task were prepared, one with all righthand turns and one with all left-hand turns.

Table 1

Descriptive Information about Participants

\begin{tabular}{|c|c|c|}
\hline Variable & Younger Adults & Older Adults \\
\hline Number & 30.0 & 24.0 \\
\hline Men & 12.0 & 12.0 \\
\hline Women & 18.0 & 12.0 \\
\hline \multicolumn{3}{|l|}{ Age (years) } \\
\hline$M$ & 20.7 & 72.3 \\
\hline Min & 18.0 & 62.0 \\
\hline $\operatorname{Max}$ & 27.0 & 84.0 \\
\hline \multicolumn{3}{|l|}{ Education (years) } \\
\hline$M$ & 13.7 & 14.5 \\
\hline$S D$ & 1.2 & 2.1 \\
\hline \multicolumn{3}{|c|}{ Biological Life Events questionnaire } \\
\hline$M$ & 0.6 & 1.0 \\
\hline$S D$ & 0.9 & 1.3 \\
\hline
\end{tabular}

Working memory task. A measure of working memory capability was obtained with the operation span task, a quantitative version of the sentence span task that has revealed significant age-related differences in other studies (e.g., Kirasic et al., 1996). This computeradministered version of the task requires that the participant read aloud a series of simple arithmetic operations involving addition, subtraction, or multiplication (example: $2+5=7$ ), which are presented on a monitor. As each operation is read, the participant must report whether the solution is correct and, regardless of these responses, must later report all of the solutions (i.e., the answers presented for all of the operations) for a particular set. Two practice trials were followed by 42 test trials, which included the presentation of three sets of two, three, four, and five operations, respectively. The experimenter wrote down the participant's oral response on each test trial. Performance was scored in terms of the total number of correct digits recalled out of the 42 possible. Previous research (Kirasic et al., 1996) has shown this task to have high reliability (.84). The results for both age groups are shown in Table 1.

Speed-of-processing task. The Digit-Symbol Substitution test from the WAIS-R was used to obtain a measure of informationprocessing speed. This measure also has revealed large, reliable age-related differences in other studies (see Salthouse, 1996). In this test, a code table of nine digit-symbol pairs is provided at the top of a page, below which are 93 double boxes that have a digit in the upper box and nothing in the attached lower box. Participants are instructed to write the proper symbol in each lower box, making reference to the code table as necessary. The total number of correctly drawn symbols in $90 \mathrm{sec}$ served as the measure of performance. The WAIS-R manual (Wechsler, 1981) reports high reliability for this test (.82). The results for both age groups are shown in Table 1.

Self-reports of events with neurologic impact. The Biological Life Events questionnaire (Houx, Vreeling, \& Jolles, 1991) was administered to all the participants to obtain a general index of insults, injuries, or experiences that have been associated with impairment of cognitive performance. The means and standard deviations for the two age groups are shown in Table 1. The magnitude of the difference suggests that it is unlikely that age-related variance in the path integration task were due to severe neurological impairment in the older participants.

\section{Procedure}

The participants were tested individually. Initially, they were briefed regarding the cognitive and physical requirements of the procedure and were asked questions about their age, general health, and handedness. The ability to see a colored $10-\mathrm{cm}$ target was assessed, as was the ability to stand directly from a wheelchair without assistance. Thereafter, all the tasks were administered in the same order.

The turn-to-target test, which was administered first, the walk-totarget task, which was administered second, and the return-to-origin task, which was administered third, were all presented in the large room, and each was preceded by a practice and training period. In the first and second tasks, the participant was instructed that a tap on the shoulder was a cue to turn or walk, respectively, to the previewed target. In training and practice for the return-to-origin task, the participant was informed that the procedure involved walking directly to a point of origin after being either led on foot or pushed in a wheelchair along segments of a walk away from that point. He or she was instructed that a tap on the shoulder would signal the time to turn and walk back to the point of origin or, in the passive locomotion condition, to stand up, pivot, and walk back to the point of origin. Three practice trials were standard. On the first, the participant walked through the procedure without either the goggles or the sound-deadening ear covers. On the second, he or she walked through the procedure without the sound-deadening ear covers, but with the goggles in place. On the third, he or she walked through the 
procedure while wearing both the goggles and the sound-deadening ear covers. The participant also was conveyed for a brief distance in the wheelchair, to become familiar with the pace of locomotion in that condition.

When the participant indicated that he or she was ready, the data collection began. On each trial, he or she was led or propelled by an experimenter who had practiced maintaining a slow, steady rate. This target rate, which had been established through pilot testing, was $0.6 \mathrm{~m} / \mathrm{sec}$. Turns were also made at a steady rate, roughly $20 \mathrm{deg} / \mathrm{sec}$, that had been established through practice. Rate of movement was not timed during data collection. The path integration trials included the six combinations of route length and turn angle, performed after both passive and active modes of transport. Within age group, the order of transport modes and the direction of turn (left vs. right) were counterbalanced. Data were collapsed across direction of turn for all data analysis.

After the return-to-origin task was completed, the participant was escorted across the hall to the small room where the Biological Life Events questionnaire, the operation span task, and the DigitSymbol Substitution test were presented. After completion of these instruments, the participant was thanked for his or her participation, debriefed, and dismissed.

\section{Data Analysis}

Initially, data from the subsidiary turn-to-target and walk-to-target tasks were examined in analyses of variance (ANOVAs) to detect a main effect or interactions involving age group on accuracy in pivoting to a previously seen target, walking to a previously seen target, and veering during walking. The $p<.05$ criterion for statistical significance was applied throughout all the analyses. No such effect or interactions were found. Thus, the results in the principal task could not be attributed to age-related differences in the ability simply to turn or walk to a previously perceived target.

Data from the principal return-to-origin task were analyzed in three ways. First, to gain an overview of the effects of age and of mode of locomotion, the linearity of executed to actual angle and executed to actual distance functions was examined. This was done using groupwise linear regression analyses and in follow-up ANOVAs performed on slopes and intercepts from individual participants' executed to actual angle and executed to actual distance functions. Second, after these regression analyses had provided the "big picture," ANOVAs were performed on signed angle error and signed distance error during return to origin, to examine possible interactions involving age group, sex of participant, and particular distances or angles involved in the task. Third, correlation and regression analyses were subsequently performed to determine the influence of working memory capability and speed of processing on age-sensitive dependent measures as determined in the ANOVAs performed on signed angle error and signed distance error.

\section{RESULTS}

\section{Relations Between Executed Angles and \\ Distances and Actual Angles and Distances}

Functions showing executed to actual angle of return to origin. An overall picture of accuracy in turning toward the point of origin was obtained by performing linear regression analyses on groupwise data for angle turned as a function of correct angle to target for each locomotion condition for separate age groups (see Figure 1). The results for the younger adults were as follows: $y=0.98 x+6.12\left(r^{2}=.61\right)$ for the walking condition and $y=0.78 x+24.71\left(r^{2}=.71\right)$ for the wheelchair condition. The corresponding results for the older adults were as follows: $y=1.01 x+7.16\left(r^{2}=.51\right)$ for the walking condition and $y=0.21 x+113.83\left(r^{2}=.23\right)$ for the wheelchair condition. Additional computations revealed that the intercept for the older adults in the wheelchair condition, but not the intercepts of the other three functions, was outside the two-tailed $95 \%$ confidence limit for intercept $=0$. Similarly, the slope for the older adults in the wheelchair condition, but not the slopes of the other three functions, was outside the two-tailed $95 \%$ confidence limit for slope $=1.00$. Thus, the functions under conditions of walking were almost identical for the two age groups and reflected accuracy in turning toward the point of origin at the end of the two route segments. The younger adults' performance in the wheelchair condition reflected a slight, consistent underestimation of return angle, whereas the older adults' performance in the wheelchair condition showed a very limited range of return angles that bore little correspondence to the actual angle of return to origin.

This account was subjected to further empirical scrutiny by performing individual linear regression analyses for each participant's angle-of-return data, deriving intercept and slope parameters, and subjecting these measures to 2 (age group) $\times 2$ (locomotion condition) ANOVAs, with Greenhouse-Geisser correction applied. The ANOVA performed on the intercepts from the angle-of-return functions revealed significant main effects of age group $\left[F(1,52)=3.85, \eta^{2}=.004\right]$ and locomotion condition $\left[F(1,52)=7.89, \eta^{2}=.007\right]$, but the interaction was not significant. The intercept for the older participants was higher than that for the younger participants $\left(64.0^{\circ}\right.$ vs. $\left.9.1^{\circ}\right)$. The intercept after the participants were pushed in a wheelchair was higher than that after they were led on foot $\left(65.2^{\circ}\right.$ vs. $\left.1.7^{\circ}\right)$.

The ANOVA performed on slopes from the angle-ofreturn functions revealed only a significant effect of locomotion condition $\left[F(1,52)=10.31, \eta^{2}=.009\right]$. Neither the effect of age group nor the interaction was significant. The slope of the function after the participants were led on foot reflected remarkable accuracy (1.05), whereas the slope after they were conveyed in a wheelchair was significantly lower (0.52).

Functions showing executed to actual distance of return to origin. An overall picture of accuracy in walking to the point of origin was obtained by performing linear regression analyses on groupwise data of distance walked as a function of correct distance to target for each locomotion condition for separate age groups (see Figure 2). The results for the younger adults were as follows: $y=0.561 x+126.04\left(r^{2}=.77\right)$ for the walking condition and $y=0.549 x+127.53\left(r^{2}=.94\right)$ for the wheelchair condition. The corresponding results for the older adults were as follows: $y=0.468 x+145.02\left(r^{2}=\right.$ $.90)$ for the walking condition and $y=0.182 x+163.65$ $\left(r^{2}=.71\right)$ for the wheelchair condition. Additional computations revealed that all four of the intercepts for these functions fell outside the two-tailed $95 \%$ confidence limit for intercept $=0$. Similar computations showed 


\section{Younger Adults}

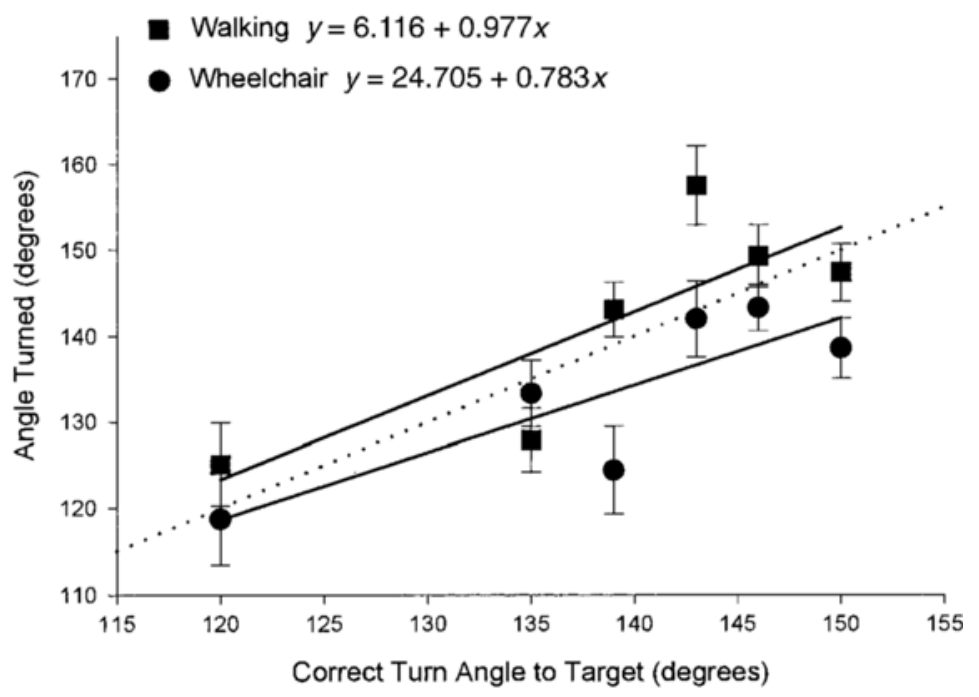

\section{Older Adults}

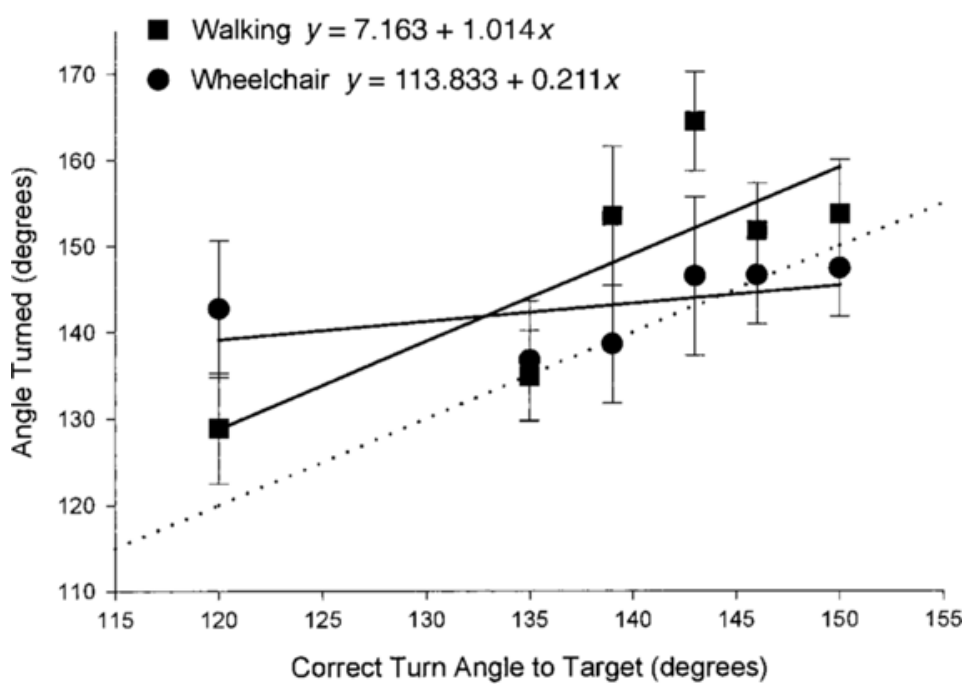

Figure 1. Angle turned as a function of angle to target for younger (upper panel) and older (lower panel) adults in the triangle completion task after they were led while walking and were conveyed in a wheelchair.

that all four of the slopes for these functions fell outside the two-tailed 95\% confidence limit for slope $=1.00$.

Performance by the younger adults in both conditions and by the older adults in the walking condition was very similar and reflected a slight tendency to walk too far when the actual distance to point of origin was small and to not walk far enough when the distance to point of origin was larger. Performance by the older adults in the wheelchair condition reflected a tendency to walk roughly the same distance back to the point of origin regardless of how far away that target actually was.

This account was further examined in 2 (age group) $\times$ 2 (locomotion condition) ANOVAs performed on inter- cepts and slopes from individual executed to actual distance functions, with Greenhouse-Geisser correction applied. Note that 2 older participants' data sets included distances (one value in one case and two in another) at which their progress was stopped to avoid collision with the laboratory walls. The ANOVA performed on intercepts revealed no significant main effects or interactions. The ANOVA performed on slopes revealed significant effects of age group $\left[F(1,51)=12.75, \eta^{2}=.011\right]$ and locomotion condition $\left[F(1,51)=9.75, \eta^{2}=.008\right]$ and a significant age group $\times$ condition interaction $[F(1,51)$ $\left.=4.06, \eta^{2}=.005\right]$. Tukey comparisons $(p<.05)$ showed that the mean slopes for the younger adults in the 


\section{Younger Adults}

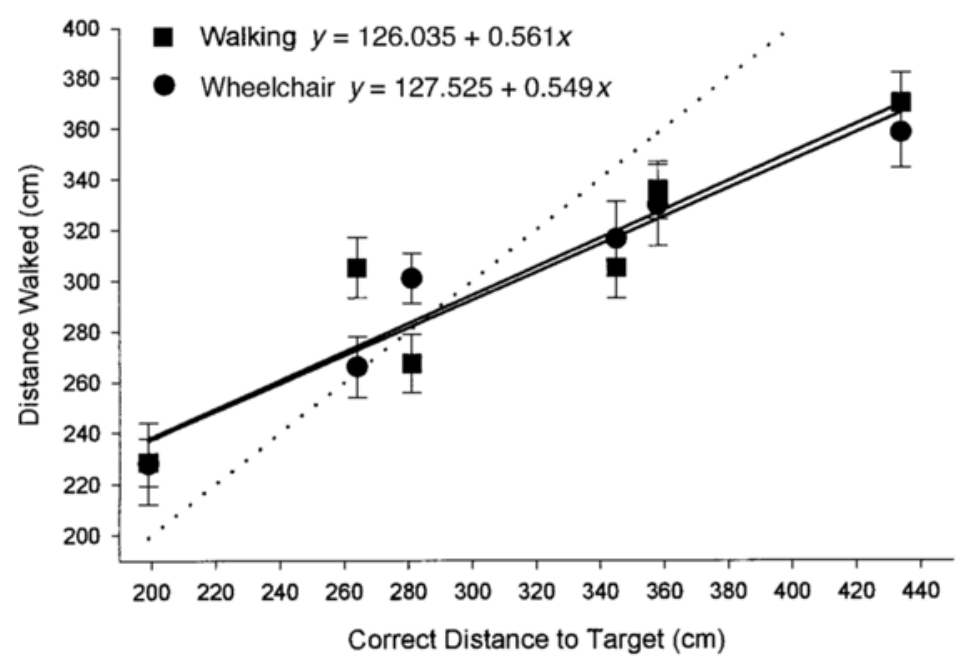

Older Adults

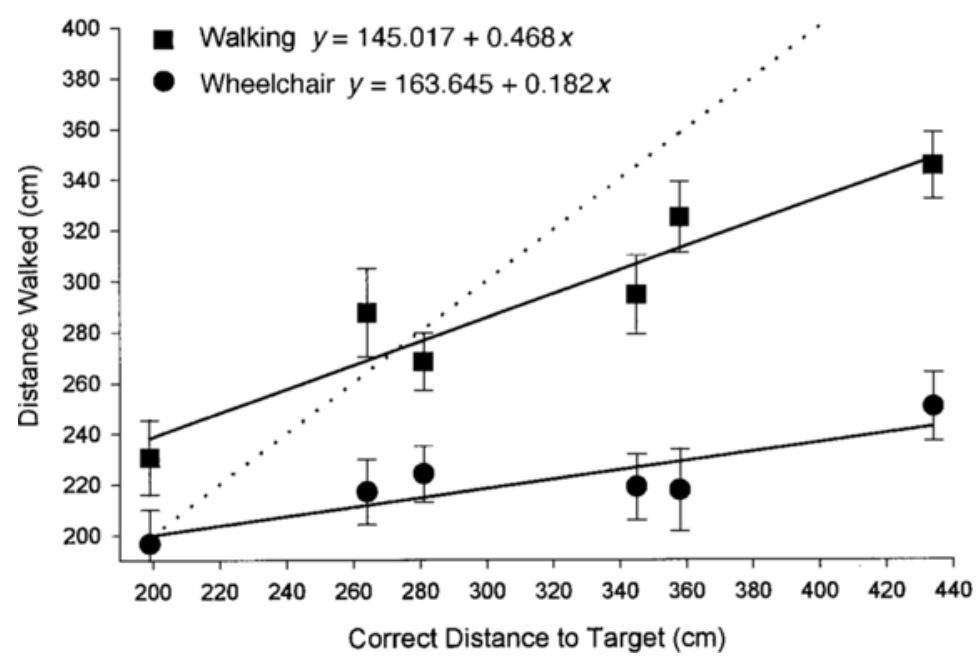

Figure 2. Distance walked as a function of distance to target for younger (upper panel) and older (lower panel) adults in the triangle completion task after they were led while walking and were conveyed in a wheelchair.

walking $(0.58)$ and wheelchair $(0.55)$ conditions and for the older adults in the walking condition (0.48) did not differ from each other significantly. However, all three of these mean slopes differed significantly from that of the older adults in the wheelchair condition (0.19).

\section{Analyses of Errors in Return Angles and Distances}

ANOVA on error of return angle. To examine specific effects of different routes traveled on angular error, a 2 (age group) $\times 2$ (sex) $\times 2$ (mode of locomotion) $\times$ 2 (length of outbound route segments) $\times 3$ (turn angle during outbound route) ANOVA was performed on signed directional error measured in degrees, with Greenhouse-Geisser correction applied. Negative values reflected travel to the left of the correct return vector; positive values reflected travel to the right of that vector. This analysis revealed a significant main effect of mode of locomotion $\left[F(1,50)=4.14, \eta^{2}=.009\right]$, which was subsumed under a significant mode of locomotion $X$ length of route interaction $\left[F(1,50)=5.46, \eta^{2}=.009\right]$. No other main effects or interactions were significant.

Tukey post hoc comparisons $(p<.05)$ were performed on the means involved in the interaction. These comparisons indicated that being led on foot along the asymmetrical route produced greater angular error $\left(\right.$ mean $=15.7^{\circ}$ ) than did being led along the shorter, symmetrical route $\left(0.9^{\circ}\right)$ or being conveyed in a wheelchair along either the asymmetrical $\left(-2.8^{\circ}\right)$ or the symmetrical $\left(0.8^{\circ}\right)$ route. 
ANOVA on error of return distance. To examine specific effects of different routes traveled on distance error, a 2 (age group) $\times 2$ (sex) $\times 2$ (mode of locomotion) $\times 2$ (length of outbound route segments) $\times 3$ (turn angle during outbound route) ANOVA was performed on signed distance errors, with Greenhouse-Geisser correction applied. Negative values reflected underestimation of the distance to origin; positive values reflected overestimation of this distance. This analysis revealed main effects of age group $\left[F(1,50)=18.81, \eta^{2}=.059\right]$, mode of locomotion $\left[F(1,50)=21.09, \eta^{2}=.036\right]$, outbound route lengths $\left[F(1,50)=57.40, \eta^{2}=.036\right]$, and outbound turn angle $\left[F(2,97)=91.01, \eta^{2}=.171\right]$. These effects were subsumed under three higher order interactions: the two-way interaction involving mode of locomotion and route length $\left[F(1,50)=17.34, \eta^{2}=\right.$ $.011]$, the three-way interaction of age group, mode of locomotion, and turn angle $\left[F(2,96)=3.74, \eta^{2}=\right.$ $.005]$, and the four-way interaction involving age group, sex, route length, and turn angle $\left[F(2,96)=6.09, \eta^{2}=\right.$ $.008]$

Tukey post hoc comparisons $(p<.05)$ were performed on the means involved in significant interactions. The mode of locomotion $\times$ route length interaction showed that conveyance in a wheelchair led to particularly poor performance with the asymmetrical, longer route $($ mean $=-76.2 \mathrm{~cm})$. Underestimation of distance was less severe in the same locomotion condition with the symmetrical shorter route $(-24.2 \mathrm{~cm})$ and in the walking condition with the asymmetrical $(-23.6 \mathrm{~cm})$ and the symmetrical $(-9.9 \mathrm{~cm})$ routes. Mean error of these three subgroups did not differ.

The three-way interaction involving age, mode of locomotion, and turn angle on the outbound route indicated that after being conveyed in a wheelchair, the older adults tended to not walk far enough, as compared with the younger adults, especially when the outbound route included certain angles that left a large distance to be walked. Specifically, in the wheelchair condition, the older adults were less accurate than the younger adults when the outbound route included a $60^{\circ}$ turn $(-156.0 \mathrm{vs}$. $-52.1 \mathrm{~cm})$ or a $90^{\circ}$ turn $(-99.3 \mathrm{vs} .-2.3 \mathrm{~cm})$, but not when the outbound route included a $120^{\circ}$ angle $(-25.1$ vs. $+15.5 \mathrm{~cm})$. After being led on foot, the older and the younger adults did not differ in terms of signed distance error, regardless of whether the angle traveled had been $60^{\circ}(-69.9$ vs. $-51.8 \mathrm{~cm}), 90^{\circ}(-22.9$ vs. $-19.3 \mathrm{~cm})$, or $120^{\circ}(+27.4$ vs. $+17.3 \mathrm{~cm})$.

Post hoc comparisons of the means involved in the four-way interaction involving age, sex, length of outbound route segments, and angle of outbound turn showed that there were only two instances in which the accuracy of men and women differed significantly, both of which involved the older participants and the $2 \times 3 \mathrm{~m}$ asymmetrical outbound route. The older women were short, in terms of return distance, much more severely than were the older men (mean signed error $=-173.7$ vs. $-94.5 \mathrm{~cm})$ after the asymmetrical route with the $60^{\circ}$ outbound turn angle, which was the route resulting in the longest return distance to origin. Also, the older women were short of the target when the actual return distance was short (i.e., after the asymmetrical outbound route with the $120^{\circ}$ outbound turn angle), whereas the older men walked slightly too far after this route $(-42.2 \mathrm{vs}$. $+19.3 \mathrm{~cm}$ ). No significant sex differences were found for either age group after the asymmetrical shorter route or for the younger adults after the asymmetrical route, regardless of outbound turn angle. In short, the asymmetrical outbound route resulted in inaccurate distances back to point of origin for the older women.

\section{Cognitive Correlates of Path Integration Performance}

Correlations between measures of cognitive resources and dependent measures from the return-to-point-oforigin task are shown in Table 2. The purpose of the correlation analysis was to identify potential mediators of age-related variance in either the direction or the distance component of path integration performance. This analysis revealed that because of the magnitude of individual differences in the direction component, only the distance component produced a reliable correlation with age. Thus, the search for mediators of age-related differences in performance focused exclusively on signed distance error as a dependent measure.

Regression analyses were performed to determine the extent to which cognitive resource measures accounted for age-related variance in signed distance error. These

Table 2

Correlation Matrix for Participant Descriptive Variables and Path Integration Performance Measures

\begin{tabular}{|c|c|c|c|c|c|c|c|c|}
\hline Variable & 1 & 2 & 3 & 4 & 5 & 6 & 7 & 8 \\
\hline 1. Age & - & & & & & & & \\
\hline 2. Sex & -.19 & - & & & & & & \\
\hline 3. Education & .21 & -.13 & - & & & & & \\
\hline 4. Biological Life Events & .16 & .11 & -.02 & - & & & & \\
\hline 5. Digit-Symbol & $-.78 *$ & $.29 *$ & -.05 & -.03 & - & & & \\
\hline 6. Operation span & $-.55^{*}$ & .08 & .01 & .17 & $.63 *$ & - & & \\
\hline 7. Signed direction error & .13 & -.01 & .03 & -.03 & -.07 & -.03 & - & \\
\hline 8. Signed distance error & $-.51 *$ & .12 & -.11 & -.11 & $.41 *$ & $.44 *$ & $.30 *$ & - \\
\hline
\end{tabular}

* Significant at $p<.05$. 
measures accounted for $71 \%$ of the age-related variance. Age by itself accounted for $R^{2}=.261$. Digit-Symbol Substitution performance alone accounted for $65 \%$ of this age-related variance, leaving only $R^{2}=.092$ attributable to age. Operation Span performance alone accounted for $60 \%$ of age-related variance, leaving only $R^{2}=.103$ attributable to age in a second step. Entered together, Digit-Symbol Substitution and Operation Span performance accounted for $71 \%$ of age-related variance in signed distance error, leaving only $R^{2}=.076$ attributable to age. In each analysis, the remaining variance attributable to age was statistically significant.

\section{DISCUSSION}

This study provides insight into age-related differences in path integration based on internal perceptual information about locomotion. The principal hypothesis under investigation was that passive conveyance in a wheelchair, which provides predominantly vestibularly based information about locomotion, would lead to impaired path integration performance, as compared with being led on foot, which provides both kinesthetically and vestibularly based information about locomotion. It was expected that the difference between locomotion conditions would be greater for older individuals than for younger ones.

The results based on the relatively constrained sampling of outbound routes used in this study showed that reliance on the vestibularly based information afforded by passive conveyance had a minor, rather than a major, impact on orientation, but they did indicate that passive conveyance had a greater effect on the older adults than on the younger ones. Regression analyses showed that, for the younger adults, mode of locomotion had no effect on return distance walked and very little effect on angle turned toward the point of origin. Both angle turned and distance walked reflected considerable relative accuracy, a fairly consistent psychological scaling of these phenomena. In contrast, regression analyses on the older adults' data suggested that both angle turned and distance walked were impacted by mode of locomotion. After walking the outbound route segments, the older adults performed very similarly to the younger individuals, but after being passively conveyed by wheelchair, they showed a severely restricted range of angles turned and distances walked. For angles, this meant that a small return angle was grossly overrotated and the remaining angles were accurate in absolute terms. For distances, this meant that the smallest distance was accurately walked and the remaining distances underexecuted in absolute terms by an increasing margin. In other words, performance was not clearly differentiated.

As was mentioned in the introduction, it can be assumed that error in encoding the outbound turn angle (or both outbound turn angle and distances) should logically lead to error in both the angle turned and the distance traveled during the return trip (Klatzky et al., 1999;
Klatzky et al., 1997; Klatzky et al., 1990; Loomis et al., 1999). The regression functions suggest that the older adults in the passive conveyance condition had difficulty in encoding the outbound angle accurately. The regression functions for the younger participants in the passive conveyance condition and both the younger and the older participants after being led on foot suggest that the turn angles were relatively accurately encoded under these circumstances. Thus, to the extent that the underlying assumptions are valid, the findings suggest an agingrelated deficit in the encoding of body rotation principally on the basis of vestibularly based information that leads to a decline in the accuracy of path integration.

The results of the ANOVAs on error data showed that particular characteristics of the outbound route interacted with other factors in influencing performanceand not always in expected ways. After passive conveyance, the older participants grossly underexecuted return distance when outbound turn angles resulted in a relatively long trip back to the point of origin. Also, outbound routes involving asymmetrical segments resulted in significant problems for the older women in terms of walking the proper distance; they walked too far when the longer route resulted in a short distance to the target and did not walk far enough when it resulted in a long distance to the target. An unexpected finding was that the asymmetric route led to a tendency for participants to overrotate when they turned to the point of origin after walking the outbound route, but not after passive conveyance. Together, these findings suggest a need for parametric studies concerned with the impact of symmetry and distances of outbound routes on performance in the triangle completion task.

The results involving cognitive correlates indicated that, to a large extent, age-related differences in path integration performance are related to cognitive resourcesspecifically, speed of processing and working memory capability. Functionally, these resources are simply an indicator of the ability to retain information temporarily while attention is switched. Thus, it is not surprising that they play a role in a large number of tasks (Kirasic et al., 1996; Salthouse, 1996). It is useful to add path integration to that list, but acknowledging age-related variance provides no clear indication of the specific limitations imposed by limited resources during task performance. The role of available processing resources in computing the direction and distance back to a target can be clarified by future studies involving direct manipulation of resource availability. If the temporary representation of the outbound route that forms the basis for each of these responses is subject to information loss through decay and interference - and it seems reasonable to posit that it is - then limiting resources or providing competing tasks at key points in the encoding process should impact path integration performance in a straightforward way.

As a whole, these results find a ready context within the growing literature concerned with the role of perceptual systems in path integration and spatial updating. 
In this regard, three points should be made. First, our findings fit well with others showing a role for kinesthetically and vestibularly based information in path integration and spatial updating (Chance et al., 1998; Loomis et al., 1993; Sholl, 1989; Waller, Loomis, \& Haun, in press) as a complement to information normally obtained through vision (Loomis et al., 1999), hearing (Loomis, Lippa, Klatzky, \& Golledge, 2002), or verbal instructions (Loomis et al., 2002).

Second, although the participants' performance in this study may have been more accurate overall than has been found in comparable studies (Klatzky et al., 1990; Loomis et al., 1993; Sholl, 1989), the higher accuracy level did not reflect a disagreement of substance regarding factors involved in path integration. It is possible that even in the absence of explicit feedback, visually guided experience in the subsidiary turn-to-target and walk-totarget tasks provided the participants in this study with a sense of the spatial dimensions of the experimental space and implicit visual memory of specific turns and distances in that space. It is also the case that the range of turn angles and distances used in this study was limited, and this factor, too, may have constrained error.

Third, the role for cognitive resources indicated by the correlational findings fit into a pattern of results suggesting that path integration and spatial updating require no cognitive resources under simple circumstances but may involve them under more demanding task conditions (Amorim, Glasauer, Corpinot, \& Berthoz, 1997; Farrell \& Thomson, 1998; Gärling et al., 1985; Lindberg \& Gärling, 1983). One of the factors that may make path integration and spatial updating less demanding cognitively is initial visual encoding of task-relevant locations. As was mentioned previously, encoding successive locations on the basis of kinesthetically or vestibularly based information is more demanding of working memory because of the temporal parameters of the encoding process.

Fourth, it must be acknowledged that the two locomotion conditions in this study were not a straightforward comparison of the effects of active versus passive conveyance. Although it is true that being pushed in a wheelchair along a novel route clearly fits the definition of passive conveyance, it is not the case that being led on foot is a purely autonomous active movement, in the sense that the participants had no choice in initiating their path of action (Philbeck, Behrmann, Black, \& Ebert, 2000). Previous research has shown that autonomous active control of locomotion has a facilitative effect on nonvisual navigation (Philbeck, Klatzky, Behrmann, Loomis, \& Goodridge, 2001). Thus, it would be reasonable to expect that differences in performance between autonomous active locomotion and passive conveyance are greater than the differences in modes of locomotion seen in the present study.

Overall, these results are not without practical implications for the study of psychological aging. They indicate that those older adults who are conveyed by passive means from place to place are at risk for spatial disorientation, especially when visual and auditory information is limited. Because aging-related difficulties with vision and hearing are not unusual, this risk factor may be applicable for a significant portion of the aged population. Also, the results suggest that sensitivity to vestibular sources of information regarding acceleration and rotation declines significantly in late adulthood. Whether tests of path integration could serve as a diagnostic for future vestibular problems, including risk for falls, is a question that merits empirical examination.

\section{REFERENCES}

AlLen, G. L. (1999). Spatial abilities, cognitive maps, and wayfinding: Bases for individual differences in spatial cognition and behavior. In R. Golledge (Ed.), Wayfinding behavior: Cognitive mapping and other spatial processes (pp. 46-80). Baltimore: Johns Hopkins University Press.

Allen, G. L., Kirasic, K. C., Dobson, S. H., Long, R. G., \& Beck, S. (1996). Predicting environmental learning from spatial abilities: An indirect route. Intelligence, 22, 327-355.

Amorim, M.-A., Glasauer, S., Corpinot, K., \& Berthoz, A. (1997). Updating an object's orientation and location during nonvisual navigation: A comparison between two processing modes. Perception \& Psychophysics, 59, 404-418.

Anooshian, L. J., \& Kromer, M. K. (1986). Children's spatial knowledge of their school campus. Developmental Psychology, 22, 854860.

BARASH, J. (1994). Age-related decline in route learning ability. Developmental Neuropsychology, 10, 189-201.

Berthoz, A., Amorim, M.-A., Glasauer, S., Grasso, R., Takei, Y., \& VIAUD-DELMON, I. (1999). Dissociation between distance and direction during locomotor navigation. In R. Golledge (Ed.), Wayfinding behavior: Cognitive mapping and other spatial processes (pp. 328348). Baltimore: Johns Hopkins University Press.

Chance, S. S., Gaune T, F., Beall, A. C., \& Loomis, J. M. (1998). Locomotion mode affects the updating of objects encountered during travel: The contribution of vestibular and proprioceptive inputs to path integration. Presence, 7, 168-178.

CoOney, R., \& ARbuckle, T. (1997). Age, context, and spatial memory: A neuropsychological approach. Aging, Neuropsychology, \& Cognition, 4, 249-265.

Etienne, A. S., Berlie, J., Georgakopoulos, J., \& Maurer, R. (1998). Role of dead reckoning in navigation. In S. Healy (Ed.), Spatial representation in animals (pp. 54-68). Oxford: Oxford University Press.

Etienne, A. S., Maurer, R., Georgakopoulos, J., \& Griffin, A. (1999). Dead reckoning (path integration), landmarks, and representation of space in a comparative perspective. In R. Golledge (Ed.), Wayfinding behavior: Cognitive mapping and other spatial processes (pp. 197-228). Baltimore: Johns Hopkins University Press.

Evans, G. W., Brennan, P. L., Skorpanich, M. A., \& Held, D. (1984). Cognitive mapping and elderly adults: Verbal and location memory for urban landmarks. Journal of Gerontology, 39, 452-457.

FARRELl, M. J., \& Thomson, J. A. (1998). Automatic spatial updating during locomotion without vision. Quarterly Journal of Experimental Psychology, 51A, 637-654.

Fujita, N., Klatzky, R. L., Loomis, J. M., \& Golledge, R. G. (1993). The encoding-error model of pathway completion without vision. Geographical Analysis, 25, 295-314.

Galliste L, C. R. (1990). The organization of learning. Cambridge, MA: MIT Press.

GärLing, T., BÖÖK, A., \& LindBERG, E. (1985). Adults' memory representations of the spatial properties of their everyday physical environment. In R. Cohen (Ed.), The development of spatial cognition (pp. 141-184). Hillsdale, NJ: Erlbaum.

GolLEdGe, R. G. (1999). Human wayfinding and cognitive maps. In 
R. Golledge (Ed.), Wayfinding behavior: Cognitive mapping and other spatial processes (pp. 5-45). Baltimore: Johns Hopkins University Press.

Houx, P. J., VReEling, F. W., \& Jolles, J. (1991). Age-associated cognitive decline is related to biological life events. In K. Iqbal, D. McLachlan, B. Winblad, \& H. Wisniewski (Eds.), Alzheimer's disease: Basic mechanisms, diagnosis, and therapeutic strategies (pp. 353358). New York: Wiley.

KIRASIC, K. C. (1991). Spatial cognition and behavior in young and elderly adults: Implications for learning new environments. Psychology \& Aging, 6, 10-18.

KIRASIC, K. C. (2000). Age differences in adults' spatial abilities, learning environmental layout, and wayfinding behavior. Spatial Cognition \& Computation, 2, 117-134.

KIRASIC, K. C. (2001). Aging and spatial behavior in the elderly adult: Past, present, and future. In R. Kitchin \& S. Freundschuh(Eds.), Cognitive mapping: Past, present, and future (pp. 166-178). London: Routledge.

Kirasic, K. C., Allen, G. L., Dobson, S. H., \& Binder, K. S. (1996). Aging, cognitive resources, and declarative learning. Psychology \& Aging, 11, 658-670.

Klatzky, R. L., Beall, A. C., Loomis, J. M., Golledge, R. G., \& PhilbeCK, J. W. (1999). Human navigation ability: Tests of the encoding-error model of path integration. Spatial Cognition \& Computation, 1, 31-65.

KLATZKY, R. L., LoOmis, J. M., \& Golledge, R. G. (1997). Encoding spatial representations through nonvisually guided locomotion: Tests of human path integration. In D. Medin (Ed.), The psychology of learning and motivation: Advances in research and theory (Vol. 37 , pp. 41-84). San Diego: Academic Press.

KlatzKy, R. L., LoOmis, J. M., Golledge, R. G., Cicinelli, J. G., DoHERTY, S., \& PELlegrino, J. W. (1990). Acquisition of route and survey knowledge in the absence of vision. Journal of Motor Behavior, 22, 19-43.

LiNDBERG, E., \& GÄRLING, T. (1983). Acquisition of different types of locational information in cognitive maps: Automatic or effortful processing? Psychological Research, 45, 19-38.

LIPMAN, P. D. (1991). Age and exposure differences in the acquisition of route information. Psychology \& Aging, 6, 128-133.

LIPMAN, P. D., \& CAPLAN, L. J. (1992). Adult age differences in memory for routes: Effects of instruction and spatial diagram. Psychology \& Aging, 7, 435-442.

Loomis, J. M., Klatzky, R. L., Golledge, R. G., Cicinelli, J. G., PelLEGRINO, J. W., \& FRY, P. A. (1993). Nonvisual navigation by blind and sighted: Assessment of path integration ability. Journal of Experimental Psychology: General, 122, 73-91.

Loomis, J. M., Klatzky, R. L., Golledge, R. G., \& Philbeck, J. W.
(1999). Human navigation by path integration. In R. Golledge (Ed.), Wayfinding behavior: Cognitive mapping and other spatial processes (pp. 125-151). Baltimore: Johns Hopkins University Press.

Loomis, J. M., LiPPA, Y., KlatzKy, R. L., \& Golledge, R. G. (2002). Spatial updating of locations specified by 3-D sound and spatial language. Journal of Experimental Psychology: Learning, Memory, \& Cognition, 28, 335-345.

McNaughton, B. L., Barnes, C. A., Gerrard, J. L., Gothard, K., Jung, M. W., KNierim, J. J., Kudrimoti, H., Qin, Y., SkagGS, W. E., SUSTER, M., \& WeAVER, K. L. (1996). Deciphering the hippocampal polyglot: The hippocampus as a path integration system. Journal of Experimental Biology, 199, 173-185.

Ochs, A. L., Newberry, J., Lenhardt, M. L., \& Harkins, S. W. (1985). Neural and vestibular aging associated with falls. In J. E. Birren \& K. W. Schaie (Eds.), Handbook of the psychology of aging (2nd ed., pp. 378-399). New York: Van Nostrand Reinhold.

Philbeck, J. W., Behrmann, M., Black, S. E., \& Ebert, P. (2000). Intact spatial updating during locomotion after right posterior parietal lesions. Neuropsychologia, 38, 950-963.

Philbeck, J. W., Klatzky, R. L., Behrmann, M., Loomis, J. M., \& GoOdRIDGE, J. (2001). Active control of locomotion facilitates nonvisual navigation. Journal of Experimental Psychology: Human Perception \& Performance, 27, 141-153.

SAlthouse, T. A. (1991). Mediation of adult age difference in cognition by reduction in working memory and speed of processing. Psychological Science, 2, 179-183.

SAlthouse, T. A. (1996). The processing speed theory of adult age differences in cognition. Psychological Review, 103, 403-428.

SAlthouse, T. A., KAusler, D. H., \& SAults, J. S. (1988). Utilization of path-analytic procedures to investigate the role of processing resources in cognitive aging. Psychology \& Aging, 3, 158-166.

Sholl, M. J. (1989). The relation between horizontality and rod-andframe and vestibular navigational performance. Journal of Experimental Psychology: Learning, Memory, \& Cognition, 15, 110-125.

UtTL, B., \& GRAF, P. (1993). Episodic spatial memory in adulthood. Psychology \& Aging, 8, 257-273.

WALler, D., LoOMIS, J. M., \& Haun, D. B. M. (in press). Body-based senses enhance knowledge of directions in large-scale environments. Psychonomic Bulletin \& Review.

WECHSLER, D. (1981). The Wechsler adult intelligence scale-revised. New York: Psychological Corporation.

WiLKNISS, S. M., Jones, M. G., KoROL, D. L., Gold, P. E., \& MANNING, C. A. (1997). Age-related differences in an ecologically based study of route learning. Psychology \& Aging, 12, 372-375.

(Manuscript received February 6, 2002; revision accepted for publication July 10, 2003.) 